Archived version from NCDOCKS Institutional Repository http://libres.uncg.edu/ir/asu/

\title{
Appalachlyan
}

$\overline{B \text { O O N E, N O R T H C A R O L I N A }}$

\section{Perspectives On Positioning, Interaction, And Learning In Small-Group Discussion: Possibilities For Extending The Analytic Lens}

\author{
By: Julie M. Kittleson and Rachel E. Wilson
}

\begin{abstract}
In this forum piece, we respond to Karin Due's study of social dynamics in groups of students in physics class and gender issues that play out in this context. We discuss two threads that appear in Due's paper: one pertains to patterns of talk within groups and how these patterns open up possibilities for learning, the other pertains to ways in which gender is constructed within groups and made visible via discourse. Our comments are intended to provide alternative ways of thinking about such issues. We hope to provide insight into how to deepen analyses of group dynamics and gender because research in both areas is important in terms of understanding how social contexts support and/or constrain learning, gender identity, and the like.
\end{abstract}

Kittleson, J.M., Wilson, R.E. Perspectives on positioning, interaction, and learning in small-group discussion: possibilities for extending the analytic lens. Cult Stud of Sci Educ 9, 469-475 (2014). https://doi.org/10.1007/ s1 1422-01 2-9440-0. Publisher version of record available at: https://link.springer.com/article/10.1007/ s1 1 422-012-9440-0 


\title{
Perspectives on positioning, interaction, and learning in small-group discussion: possibilities for extending the analytic lens
}

\author{
Julie M. Kittleson • Rachel E. Wilson
}

Received: 17 June 2012/ Accepted: 28 July 2012/Published online: 18 September 2012

(C) Springer Science+Business Media B.V. 2012

\begin{abstract}
In this forum piece, we respond to Karin Due's study of social dynamics in groups of students in physics class and gender issues that play out in this context. We discuss two threads that appear in Due's paper: one pertains to patterns of talk within groups and how these patterns open up possibilities for learning, the other pertains to ways in which gender is constructed within groups and made visible via discourse. Our comments are intended to provide alternative ways of thinking about such issues. We hope to provide insight into how to deepen analyses of group dynamics and gender because research in both areas is important in terms of understanding how social contexts support and/or constrain learning, gender identity, and the like.
\end{abstract}

Keywords Group dynamics $\cdot$ Discourse $\cdot$ Gender $\cdot$ Positioning

Researchers have shown great interest in understanding gender dynamics associated with sciences in which women are traditionally underrepresented, such as physics. Given the interest in this topic, Karin Due's (2012) study is noteworthy because of the focus on social dynamics in groups of students in physics class and the attention given to gender issues. Two threads are evident in Due's paper: one pertains to patterns of talk within groups and how these patterns open up possibilities for learning, the other pertains to ways in which

Lead Editors: K. Scantlebury and A. Hussénius.

This forum essay synthesizes and expands upon issues raised in Karin Due's forum published in Cultural Studies of Science Education. doi:10.1007/s11422-012-9441-z.

\section{J. M. Kittleson (ه)}

Department of Mathematics and Science Education, The University of Georgia,

212 Aderhold Hall, Athens, GA 30605, USA

e-mail: jkittl@uga.edu

R. E. Wilson

Department of Curriculum and Instruction, Appalachian State University,

Edwin Duncan Hall, Boone, NC 28608, USA

e-mail: wilsonre3@appstate.edu 
gender is constructed within groups and made visible via discourse. In the first part of this response, we discuss what we see as the usefulness of attending to talk within groups. Next, we discuss ways to enhance the analysis of gender dynamics. While Due's analysis certainly does shed light on both group discourse and gender dynamics, our comments are intended to provide alternative ways of thinking about such issues. We discuss examples of how we, along with other researchers, have addressed these concerns. While some of the issues we discuss are outside the scope of Due's analysis, we hope to provide insight into how to deepen analyses of group dynamics and gender, because research in both areas is important in terms of understanding how social contexts support and/or constrain learning, gender identity, and the like.

\section{Examining patterns of talk within groups}

One of the strengths of Due's analysis is the focus on the discourse generated by students working within collaborative groups. Various researchers have described connections between learning and social interaction among learners. The analysis presented by Due, in which she examines the actual talk between group participants, is important in terms of understanding how the social setting of the classroom supports student learning by attending to the discourse shared among participants. An advantage of this approach is that it allows researchers to examine the actual words and comments uttered in a particular context and how participants contribute to the evolving conversation. Data of this nature can be useful in terms of understanding how opportunities for participation, learning, and so forth are supported and/or constrained via social interaction.

A study by Sherry Southerland, Julie Kittleson, John Settlage, and Kimberly Lanier (2005) provides an example of a social interaction analysis and illustrates how social interaction impacted students' opportunities for learning. In this study, the authors followed third grade students during an investigation of condensation and compared the discourse that ensued in class with measures of students' conceptions of condensation. This analysis was framed using the emergent perspective (Cobb and Yackel 1996), a framework in which the social plane and the individual plane are reflexively connected. At the outset of the study the authors asked students to respond to a scenario about condensation. Students' responses were used to determine their understandings of condensation. Next, the conversations that ensued while students participated in an investigation about condensation were recorded. The authors focused specifically on two groups of students. A few days after the investigation, students were interviewed about their ideas about condensation; they also completed a delayed post-test. All these data points were combined in a way that allowed the researchers to track each student's conceptions of condensation at different points. This analysis yielded a description of if and how students' conceptions were shaped by the conversation that ensued in the group, as well as a description of how social factors shaped group discourse.

Southerland et al.'s (2005) study was conducted in an urban elementary school. Drawing on the work of Beth Warren, Cynthia Ballenger, Mark Ogonowski, Ann Rosenbery, and Josiane Hudicourt-Barnes (2001), the authors took into consideration the everyday resources upon which students drew. In terms of working with students from diverse backgrounds, it is important to take into account how students draw on resources when their "everyday ways of knowing and talking are seen as being the furthest from those traditionally valued in school science" (Warren et al. 2001, p. 531). While considering ways in which students' discourse patterns were congruent and/or incongruent with established ways of knowing physics was 
outside the purview of Due's analysis, we mention it because taking into account such congruence and incongruence can reveal how students construct themselves (and are constructed by others) as competent students and/or scientists.

The groups of third graders included in Southerland et al.'s study were heterogeneous in terms of gender and academic level. Students were asked about which of their peers they thought could help them with science, which provided some measure of status among peers. It was noted that:

When students who were perceived to be academically weaker by their peers presented their ideas or attempted to become active participants in groups discussions, they often were marginalized, and their ideas typically failed to impact the group meaning-making process....contributions made by students perceived as academically weaker had scant possibility of becoming the focus of group meaning-making, regardless of the rhetorical move employed. (Southerland et al. 2005, p. 1043)

With respect to Due's paper, it may be the case that taking into account students' social standings relative to one another plays a role in how students respond to each others' contributions and how some people were constructed as competent physics students while others were not.

A noteworthy issue discussed by Due, and one that relates to understanding how social interaction provides opportunities for learning, pertains to the quality of talk among members of a group. If researchers believe that interaction on the social plane can foster learning (as with the Emergent Perspective (Cobb and Yackel 1996)), then it is helpful to see the range of conversations that happen between group members to understand how conversations evolve based on what contributions are made by whom.

Julie Kittleson and Sherry Southerland (2004) conducted an analysis of discourse produced by a group of college-level engineering students who were working on an authentic engineering project for their senior capstone design course. A purpose of the analysis was to examine how knowledge was co-constructed within the group and determine what factors impacted co-construction of knowledge. The authors described the target for examining how ideas were co-constructed as concept negotiation, which was a particular form of conversation in which there was a give and take between participants as they discussed concepts that were relevant to the task at hand. Concept negotiation was identified during instances in which group members attempted to figure out what factors impacted the airflow in an automobile windshield defroster. In terms of understanding coconstruction of knowledge, the authentic nature of the group's task likely enabled instances of concept negotiation because the students working on this project were charting new territory. However, concept negotiation was somewhat rare. The project necessitated that the group spend a considerable amount of time constructing the experimental apparatus (a model of a heating/cooling system in a car), as well as designing an analogous computer model. There was much procedural talk that accompanied this aspect of the task. Building the models was an integral part of this group's work. Yet the conversations that were most informative in terms of understanding how ideas were made available on the social plane and how the group co-constructed knowledge tended to happen when the group encountered unexpected findings when examining the results of their tests. While instances of concept negotiation were relatively rare, these instances were very insightful in terms of understanding how participants responded to one another's contributions and how their ideas evolved throughout the course of interaction.

While it is important to consider the content of talk (e.g., the actual words a person utters during interaction) it can be equally as important to consider unspoken aspects of discourse. 
The analysis conducted by Kittleson and Southerland (2004) incorporated James Gee's (1999) perspective on discourse analysis, which he calls Discourse analysis. From this perspective, language is comprised of much more than the words uttered. As such it is, "not just a matter of being able to 'talk science' (Lemke 1990), but also a matter of using appropriate forms of inquiry, appropriate forms of evidence, and other appropriate ways of knowing and doing that comprise a disciplinary Discourse" (Kittleson and Southerland 2004 , p. 270). Depending on how the analysis is framed, there are various ways to examine how people are positioned via interaction. For example, Due's intention was to describe how "interaction with peers, in a physics learning community, influences the student's chances of being viewed as a student skilled in physics" (paragraph 4). In terms of how students are viewed, one issue Due discusses is gender. At this point in the paper, we turn our attention to issues pertaining to gender and ways in which gender is theorized and analyzed.

\section{A deeper theoretical perspective for analysis of gender dynamics}

In addition to analyzing the types of talk in which students were engaged, Due examined the influence of gender on the positioning of students as competent physics students. In the introduction to the paper, Due referred to the following ideas from the literature concerning gender theory: gender symbolism, gender structure and individual gender, and hegemonic masculinity. An aspect that could be strengthened in Due's analysis is a description of how each of these ideas relate to one another within a comprehensive research framework. With respect to Due's analysis, we were interested in understanding why the author selected these issues as ones that were consistent with, and applicable to, a study focused on discussions and positioning. We raise this issue not because we are critical of her data or research design, but because we felt that having this information would be helpful in terms of understanding how Due was positioning her own work in relation to gender theory.

Research focusing on the influence of gender in social learning settings is an important area of study. Gender research that does not use gender theory as a foundation, however, runs the risk of appearing under-theorized and thus, under-analyzed. Gender researchers in science education should make explicit their understanding of gender as a necessary part of their research framework. Knowing the author's own theoretical stance on gender helps readers understand the choice of the body of literature from which an author is drawing. For example, some gender researchers believe that gender differences are a result of biological differences in sex, some from differences in socialization, and some from different cultural ideals for each gender role. All of these stances are supported by gender theory and research, but they also dictate different kinds of research questions concerning the influence of gender. Without a comprehensive research framework, the reader is left wondering how the researcher is using theoretical ideas of gender symbolism, gender structure, and individual gender; thus, introducing the possibility of critiquing such research on the grounds that data are under-theorized.

An example of one gender theorist that integrates these ideas is Barbara Risman (1998). While other gender theorists provide frameworks that are useful for thinking about the salience of gender as a structural influence, Risman's (1998) three-part gender as structure is beneficial because it encompasses the work of other gender theorists and researchers (for example, Sandra Bem (1993), Nancy Chodorow (1995), and Raewyn Connell (1987)) and encourages researchers to examine the influence of gender at three levels of society: institution, interactions, and the individual. Risman (1998) discussed how the categorization of people based on gender becomes part of the structure of society because it can be 
mediated at each of these levels. Yet Risman recognized that the level of interactions may be particularly important in how gender categorization is reinforced in daily life.

We believe that Risman's (1998) gender as structure would be an applicable theoretical element in a comprehensive research framework for Due's gender analysis because it integrates ideas such as gender symbolism, gender structure, and individual gender. For example, in Risman's (1998) framework, gender structure occurs at three different levels, one of which is the level of the individual. In addition, gender symbolism comes into play at all three levels of gender as structure when cultural ideas about gender influence institutional structure, how people interact with each other, and how they see themselves. Given that the bulk of Due's data is focused on how students interact with one another in a physics classroom setting, Risman's (1998) focus on gender structure at the level of interactions would be helpful for thinking about how gender symbolism influences students interactions in social learning settings. Due's data set does not lend itself to an analysis of students' individual gender, however, and therefore, might be left aside for another study or another analysis.

An example of how a comprehensive framework involving gender theory was used in science education is Heidi Carlone and Angela Johnson's (2007) study of minority female science students. In a longitudinal study of their participants, Carlone and Johnson (2007) integrated practice theory literature used in science education research (Eisenhart and Finkel 1998) with research literature on identity in mathematics and science education. They constructed a model of science identity that took into account the performance of students, recognition of students as a "science person", and their competence as science students. They argued that each of these aspects influenced and were influenced by students' racial, ethnic, and gender identities. In this way, Carlone and Johnson (2007) linked analyses of individual gender and gender in interactions to understand how gender was a social influence in science learning settings. Their discussion of how cultural production theory influenced their model and their analysis of their data is an example of how these researchers explicitly positioned their work amongst other gender research in the field of science education so that we as readers can understand how their interpretations relate to other research studies and evaluate whether or not their framework is an appropriate fit for their research questions.

Rachel Wilson's (2011) study of female first-generation college students is another example of a how gender ideas can be theorized to give readers information in order to understand how authors are using and applying ideas in analysis from gender theorists. Like Carlone and Johnson (2007), Wilson used practice theory (Holland and Eisenhart 1990) to explicitly describe her stance on gender as a cultural construction. In addition, Wilson used Bem's (1993) ideas of gender categorization and gender polarization, which are incorporated into Risman's (1998) gender as structure as a part of her comprehensive research framework to illustrate her stance on gender as a cultural construction. Wilson's analysis of interview data with female first-generation college students and science majors focused on the students' own interpretations of how gender influenced their interactions with their families, peers, and instructors and their goals as science majors. In this way, Wilson (2011) made a concerted effort to build a comprehensive research framework that explicitly illustrated her stance on gender, used gender theory that supported her stance on gender to develop research questions, and applied ideas from this literature to analyze data. This consistency between a research framework and analysis gives readers a clearer picture of what the researcher is trying to accomplish and allows the reader to evaluate whether or not they think that the researcher has accomplished her/his research goals. 
Gender research in science education is well-theorized and analyzed when comprehensive research frameworks include gender theory and research literature in science education. As a community, we should make sure that we ask researchers to position their work within gender theory more explicitly in order to encourage deeper thinking about gender as an influence in science, as well as to encourage deeper understandings of the range of stances on gender and how they each contribute to our developing understandings of gender as an influence in science.

\section{Conclusion}

Overall, we appreciate Karin Due's work to provide a detailed description of group discourse, particularly paying attention to how conversations evolve in learning contexts. Analyses of this nature can illuminate ways in which social processes support and/or constrain learning. While Due's data and analysis are fruitful in terms of addressing important questions in science education, we would suggest the author attend to dimensions of discourse that go beyond verbal aspects of talk as well as articulate a deeper theoretical perspective concerning gender theory. We intended to provide examples of ways researchers have attended to these areas of research in order to illustrate thinking about social interaction and gender in ways that might help to push boundaries of the work and the field of science education.

\section{References}

Bem, S. L. (1993). The lenses of gender: Transforming the debate on sexual inequality. New Haven, CT: Yale University Press.

Carlone, H. B., \& Johnson, A. (2007). Understanding the science experiences of successful women of color: Science identity as an analytic lens. Journal of Research in Science Teaching, 44, 1187-1218.

Chodorow, N. (1995). Gender as personal and cultural construction. Signs, 20, 516-544.

Cobb, P., \& Yackel, E. (1996). Constructivist, emergent, and sociocultural perspectives in the context of developmental research. Educational Psychologist, 31, 175-190.

Connell, R. W. (1987). Gender and power: Society, the person, and sexual politics. Stanford, CA: Stanford University Press.

Eisenhart, M. A., \& Finkel, E. (1998). Women's science: Learning and succeeding from the margins. Chicago, IL: The University of Chicago Press.

Gee, J. P. (1999). An introduction to discourse analysis. New York: Routledge.

Holland, D., \& Eisenhart, M. (1990). Educated in romance: Women, achievement, and college culture. Chicago, IL: The University of Chicago Press.

Kittleson, J. M., \& Southerland, S. A. (2004). The role of discourse in group knowledge construction: A case study of engineering students. Journal of Research in Science Teaching, 41, 267-293.

Lemke, J. (1990). Talking science. Norwood, NJ: Ablex.

Risman, B. J. (1998). Gender vertigo. New Haven, CT: Yale University Press.

Southerland, S., Kittleson, J., Settlage, J., \& Lanier, K. (2005). Individual and group meaning making in an urban third grade classroom: Red fog, cold cans, and seeping vapor. Journal of Research in Science Teaching, 42, 1032-1061.

Warren, B., Ballenger, C., Ogonowski, M., Rosenbery, A. S., \& Hudicourt-Barnes, J. (2001). Rethinking diversity in learning science: The logic of everyday sense-making. Journal of Research in Science Teaching, 38, 529-552.

Wilson, R. E. (2011). Exploring the experiences of female first-generation college students as science majors: How gender, race, and class shape persistence in the figured world of academic science departments. Unpublished doctoral dissertation, The University of Georgia. 


\section{Author Biographies}

Julie M. Kittleson is an Assistant Professor in the Department of Mathematics and Science Education at the University of Georgia. Her interests include elementary science teacher education and science learning in the elementary grades.

Rachel E. Wilson is an Assistant Professor in the Department of Curriculum and Instruction at Appalachian State University. Her interest involves influences of cultural ideas (such as about gender) in science learning contexts. 